\title{
Evaluation of the Nutritional Status of a Rural Parasitized Pediatric Population in the State of Guerrero, Mexico
}

\author{
Ignacio Martínez-Barbabosa ${ }^{1}$, Hilda Ortiz Pérez ${ }^{1}$, Marcos Aguilar Venegas ${ }^{1}$, Rebeca Cordova \\ Moreno $^{2}$, Enrique Gaona ${ }^{2}$, Ana María Fernandez Presas ${ }^{3 *}$ \\ ${ }^{1}$ Department of Health Care, Universidad Autónoma Metropolitana, Xochimilco, México City, México \\ ${ }^{2}$ Department of Biological Systems, Universidad Autónoma Metropolitana, Xochimilco, Calzada del Hueso 1100 Col.Villa Quietud, Coyoacán, México City, \\ México
}

Received: June 20, 2015; Accepted: September 21, 2015; Published: September 30, 2015

*Corresponding author: Ana María Fernández-Presas, Department of Microbiology and Parasitology, Faculty of Medicine, National Autonomous University of Mexico, Mexico City, Mexico.Pin: 04510; Email: presas@unam.mx

\begin{abstract}
Introduction: Evaluation of the nutritional status of the pediatric population must be performed frequently, mainly in socioeconomic excluded regions, where lack of basic services, malnutrition, and enteroparasitoses can affect the immunological development of children and facilitate infections.

Objective: To evaluate the nutritional status of a rural pediatric population in the state of Guerrero, Mexico.

Material and Methods: We studied 250 children, aged between 2 and 12 years. Three parasitoscopic (PS) examinations were performed for each child, and their nutritional status was evaluated (body mass index, BMI).

Results: In $82.4 \%$ of children, the BMI was between 15 (kg/ $\mathrm{m}^{2}$ ) and $17\left(\mathrm{~kg} / \mathrm{m}^{2}\right)$. Severe malnourishment (46.4\%) prevailed in all children. The BMI of 4-year-old children was significantly lower than that of 10- to 12-year old ones $(p<0.05)$. Prevalence of parasites was of $68 \%$. Entamoeba coli, Entamoeba histolytica, Giardia lamblia, Blastocystis hominis, Iodamoeba butschlii, Endolimax nana, Enteromonas sp., Hymenolepis nana, Hymenolepis diminuta, Ascaris lumbricoides, Ancylostomatidae and Trichuris sp., were identified. The presence of $E$. coli was significant in the different age groups, $p<0.021$. In children of the 1st, $2 \mathrm{nd}$, and $3 \mathrm{rd}$ grades the presence of $E$. coli and $E$. histolytica was significant, $p<0.015$ and $p<0.016$, respectively.

Conclusions: The prevalence of malnutrition and intestinal parasitism observed in this study was high. It is necessary to increase this type of epidemiological studies that may contribute to a more precise knowledge of the causality between nutritional factors and parasitoses. Administration of anti-parasitic agents is recommended every three months in communities with a high frequency of parasitoses, as well as the implementation of environmental sanitation measures.
\end{abstract}

Keywords: BMI; Parasitoses; Children; Epidemiology

\section{Introduction}

The nutritional status should be evaluated frequently, mainly in the pediatric population that lives in tropical regions and developing countries [1,2]. The determining factors of the incidence and severity of child malnutrition are multiple and many times result from the sum of several of them. Among these factors, stand out the miserable conditions in which they live, the high birth rate, the hypoproteic diet, the deficient supply of vitamins and minerals, the intestinal malabsorption resulting from parasite infections and chronic diseases [3]. Parasite infections are an important public health problem, as they cause anemia due to iron deficiency, malabsorption of nutrients and diarrhea, among the main ailments [4]. The high prevalence of parasitoses is often associated with fecal contamination of drinking water and the soil, or of food, together with deficient sanitary and socio-cultural conditions $[1,5]$.

Child malnutrition occurs more frequently in homes of excluded rural communities, in which poverty adds to the lack of information and the difficulties in food supply faced by the most isolated populations, in which deficiencies in housing quality, environmental sanitation, potable water supply, sewage systems, or personal and collective hygiene practices abound. The problem is so severe, that [6], state that 10 million children die each year, and almost all of them in poor countries. The death of 5 million children less than 5 years is associated to malnutrition, and almost 2 million deaths to intestinal infections. The mortality rates are higher in children from 6 to 12 months of age, because at this age the immune system has not reached maturation, antibodies diminish in maternal milk, and the food introduced during weaning can be contaminated with diverse parasites [6-8]. There is a close association between intestinal parasitoses and nutrition. Intestinal parasitoses deteriorate the nutritional status of the host, which can exacerbate and even cause severe malnutrition with extreme repercussions on growth and psychomotor development when occurring at an age under 2 years. In addition, there are alterations in cellular immunity and, in consequence, an increase in the duration and severity of infections at different life stages $[9,10]$. This association contributes largely to the high morbidity indices. 
In Mexico, just like in countries with similar socioeconomic characteristics, intestinal parasitoses and malnutrition are considered public health problems [3]. To understand their importance, it must be pointed out that the General Direction of Epidemiology reports parasitoses within the 20 principal causes of morbidity and mortality. Among them, those caused by helminths occupy the 7 th place in the population of 4 to 8 years of age, with 57744 cases per 100000 inhabitants, and in the 10 to 14 years group at the 9th position with an incidence of 18645 cases. Chronic malnutrition (low size, low weight) in the country amounts to $13.6 \%$, representing 1.5 million children less than 5 years of age with low weight $(2.8 \%)$ and emaciation in $1.6 \%$ [11]. This fact becomes more acute in socioeconomic excluded rural populations that live in extreme poverty, where intestinal parasitoses have been reported at frequencies of $53.2 \%$ [12], $62.8 \%$ [13] and $67 \%$ [14].

The objective of this work was to evaluate the relation between the nutritional status and parasitic infections in children living in a socioeconomic excluded rural community of the state of Guerrero, Mexico.

\section{Material and Methods}

Huajintepec is located in the municipality of Ometepec, in the state of Guerrero, Mexico, at GPS coordinates: length (dec): -98.230000; latitude (dec): 16.609444 at $330 \mathrm{~m}$ above sea level. The population of Huajintepec was originally indigenous; currently Mestizos predominate with a total population of 2345 inhabitants, 1164 men and 1181 women. It has 541 living quarters, 275 with soil floor, and 124 have only one room; 89 people live in indigenous homes, 310 of all dwellings have sanitary installations, 447 are connected to public services, 515 have access to electricity. Their diet is generally based on corn, pumpkin, rice, beans, and chilies. Corn is cultivated manually under the slash-and-burn system, using a machete, pickaxe, and rarely ox teams. Some inhabitants raise bovine and caprine cattle, but at a low scale. In general, the population depicts precarious sanitary conditions; some families has no sewage. Regarding potable water, most families drink water from the well or river, they do not boil the water despite their saying the contrary [15].

\section{Study design}

During September 2013, a descriptive exploratory, crosssectional study was performed aimed at evaluating the nutritional status of a sample of the child population of Huajintepec, Guerrero. We studied 250 children from 2 to 12 years of age. They were subjected to a series of three parasitoscopic (PS) tests, and their nutritional status was assessed.

The people were reached by addressing the school authorities in an elementary school, where informative and explanatory talks were given, initially addressing school authorities and teachers, and then involving parents and students to generate interest and get them involved in the study. During the talks, the parents and/or tutors received an informed consent form to authorize the participation of their children in the study. They were briefed on how to gather the fecal sample and were given polypropylene recipients with screw-on lids containing $50 \mathrm{~mL}$ of $10 \%$ formaldehyde diluted in isotonic saline solution. Studies complied with the Helsinki Declaration [16]. A collection of fecal samples labeled with the name, age, gender, and school grade was performed at the school facilities. At the time of reception, samples were placed in a portable cold network for their transport to the Laboratory of Human Parasitology of the Universidad Autónoma Metropolitana-Xochimilco (UAM-X), in Mexico City.

\section{Evaluation of the nutritional status}

To assess the nutritional status of the children, the Body Mass Index (BMI) was used; this measures the association between weight and height. It is calculated by dividing the weight in kilograms by the height in Meters squared $\left(\mathrm{kg} / \mathrm{m}^{2}\right)$. Weight and size were obtained with a pedestal scale provided with a stadiometer (Torino), and an accuracy of $100 \mathrm{~g}$. The techniques to obtain the weight and height of each child included: each child was weighed with the minimal amount of clothes and without shoes. In a firm standing position they were placed in the middle of the scale, that is, with ankles touching and the tips of feet separated $45^{\circ}$ between them, the back straight, arms hanging on the sides naturally and the gaze to the front, aiming at the external orifice of the auditory conduct and the lower margin of the orbit were in a parallel plane to the surface of the floor. Once in correct position, the horizontal bar of the stadiometer was placed on the sagittal suture of the skull to measure height. Once the BMI had been obtained, the nutritional status of each child was categorized according to the parameters of WHO [4] Table1.

Parasitoscopic examination: The parasitoscopic (PS) tests were performed at the Laboratory of Human Parasitology of UAM-X. Each fecal sample was processed individually by the concentration flotation with zinc sulfate at 1.18 (Faust) methods. Microscopic analysis was performed under clear field microscopes (Carl Zeiss) at 100 and 400 magnifications. Identification of parasites was made according to their morphological characteristics.

\section{Statistical analyses}

The obtained data were organized and coded in SPSS software. Frequencies and contingencies tables were elaborated. In addition, statistical association tests were applied (X2 and Fisher's exact test) with a confidence interval (CI) of 95\%. BMI was related to age, gender, and the presence of parasites.

\section{Results}

This study included 250 children; the distribution according to gender was very similar; $50.8 \%$ corresponded to boys and $49.2 \%$ to girls. Low weight was found in $82.4 \%$ of children, and $68.0 \%$ were parasitized. Figure 1 shows the distribution of the frequencies obtained for the BMI evaluation of the studied population. As observed, most children were between $15(\mathrm{~kg} /$ $\left.\mathrm{m}^{2}\right)$ and $17\left(\mathrm{~kg} / \mathrm{m}^{2}\right)$, these values are below $24.99\left(\mathrm{~kg} / \mathrm{m}^{2}\right)$ of BMI, considered as normal weight according to the parameters indicated by WHO (Table 1). The encountered values correspond clinically to the third and second-degree of malnutrition, 


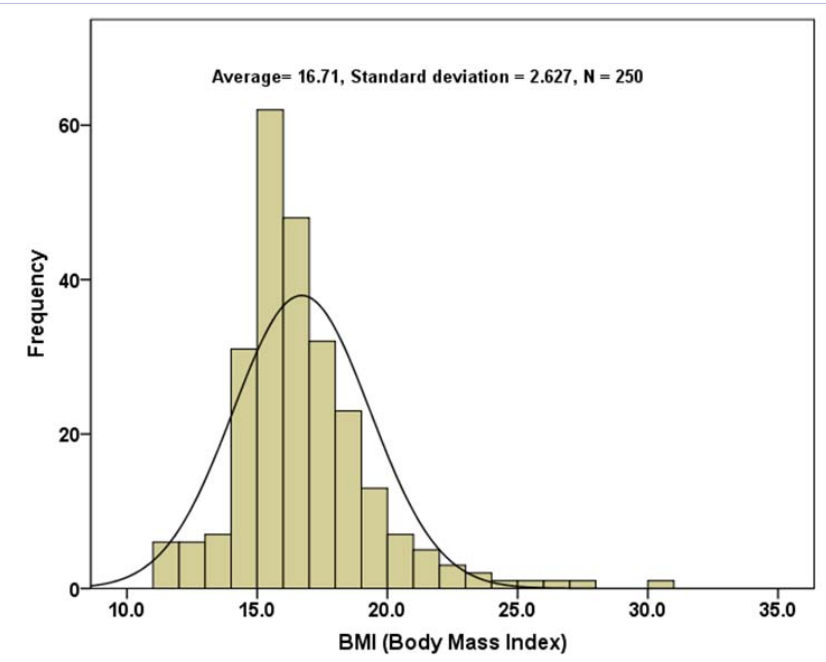

Figure 1: Frequency distribution of BMI in children of Huajintepec, Guerrero.

Table 1: WHO classification of nutritional status according to BMI.

\begin{tabular}{|l|l|l|}
\hline Classification & IMC $\mathbf{~} \mathbf{k g} / \mathbf{m}^{\mathbf{}} \mathbf{)}$ & \\
\hline & Core Values & Additional Values \\
\hline low weight & $<18,50$ & $<18,50$ \\
\hline severely underweight & $<10,00$ & $<16,00$ \\
\hline mild thinness & $<16,00$ & $<16,00-16,99$ \\
\hline Normal & 18,5 & $18,5-22,99$ \\
\hline overweight & $\geq 25,00$ & $\geq 25,00-24,99$ \\
\hline pre-obese & 25,00 & 25,00 \\
\hline obesity & $\geq 30,00$ & $27,50-29,99$ \\
\hline mild obesity & $30,00-34,99$ & $30,00-32,49$ \\
\hline average obesity & $35,00-39,99$ & $35,00-37,49$ \\
\hline morbid obesity & $\geq 40,00$ & $\geq 40,00$ \\
\hline
\end{tabular}

Source: Adapted from WHO, 1995, 2000 and WHO2004

respectively. Severe low weight $<16.00\left(\mathrm{~kg} / \mathrm{m}^{2}\right)$ is considered as second-degree malnutrition and was found in $46.4 \%$ of all children (Figure 2). Results, in general, showed that the BMI of 4-year-old children was significantly lower than that presented by children of 10 to 12 years, $p<0.05$ (Figure 3). A $68.0 \%$ of children were parasitized, with predominance in children of 6 to 8 years of age. Table 2 shows the frequencies and percentages of the found protozoan and helminths. As observed, the total frequency of commensal protozoan and parasites was of 203 $(81.2 \%)$ and of helminths was $75(30.0 \%)$. The percentage of the different identified species was: Entamoeba coli, 39.6\%; Entamoeba histolytica, 17.2\%; Giardia lamblia, 11.2\%; Blastocystis hominis, 7.2; Iodamoeba butschlii, 4.4\%; Endolimax nana $1.2 \%$; Enteromonas sp., 0.4\%; Hymenolepis nana, 16.4\%; Hymenolepis diminuta, 1.2\%; Ascaris lumbricoides, 8.8\%;
Ancylostomatidae 2.4\% and Trichuris sp., 1.2\%. The percentage of polyparasitized children, that is, with more than one species was 43; monoparasitized, 14.4\%; biparasitized, 7.6\%; triparasitized, $2.0 \%$; tetraparasitized and pentaparasitized, $0.2 \%$. Table 3 shows the results for $E$. coli in the different age groups, $p<0,021$. Results according to age groups showed the presence of $E$. coli in school children of the first, second, and third grade with a $p<$ 0.015. E. histolytica was identified in the same age groups at $p<$ 0.016 (Table 5).

\section{Discussion}

Prevalence of parasitoses and malnutrition in Mexico, like in many developing countries, is related to exposure to unhealthy environments that foster the presence, persistence, and dissemination of intestinal parasites, as well as to the

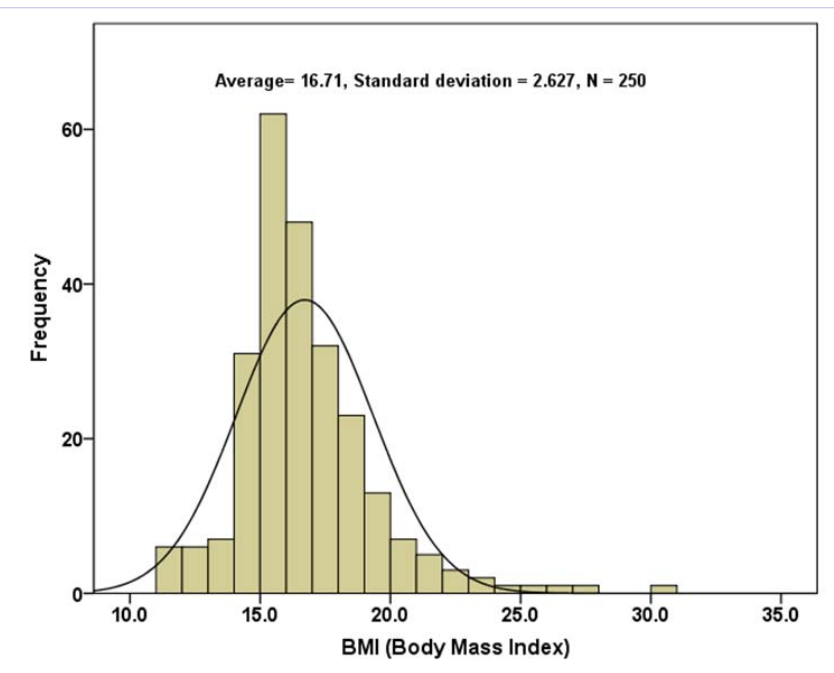

Figure 2: Distribution of the prevalence of BMI in 250 children from Huajintepec, Guerrero. Mexico.

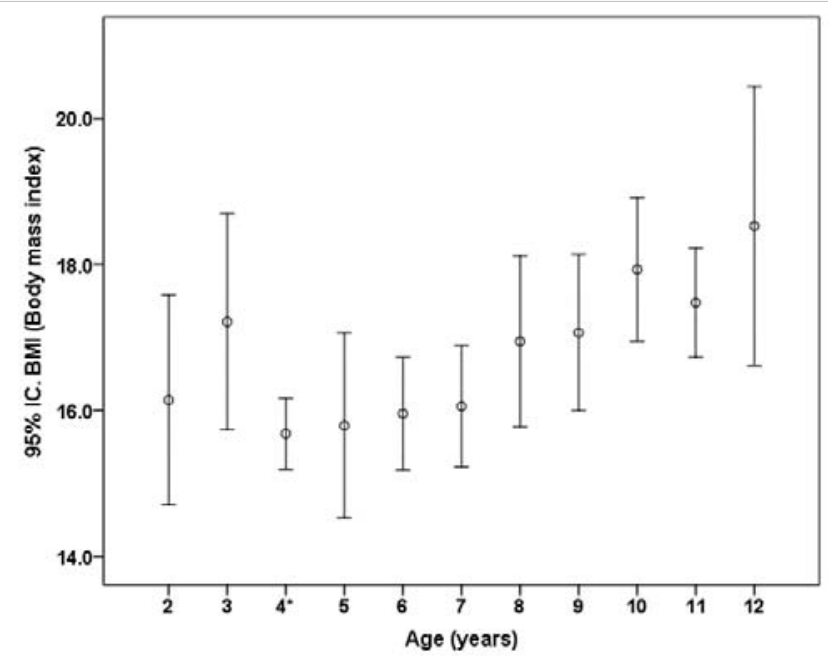

Figure 3: BMI by age group of the 250 children form Huajintepec, Guerrero, Mexico.

$* p<0.05$ in children 4 years relative to those of $10-12$ years. 


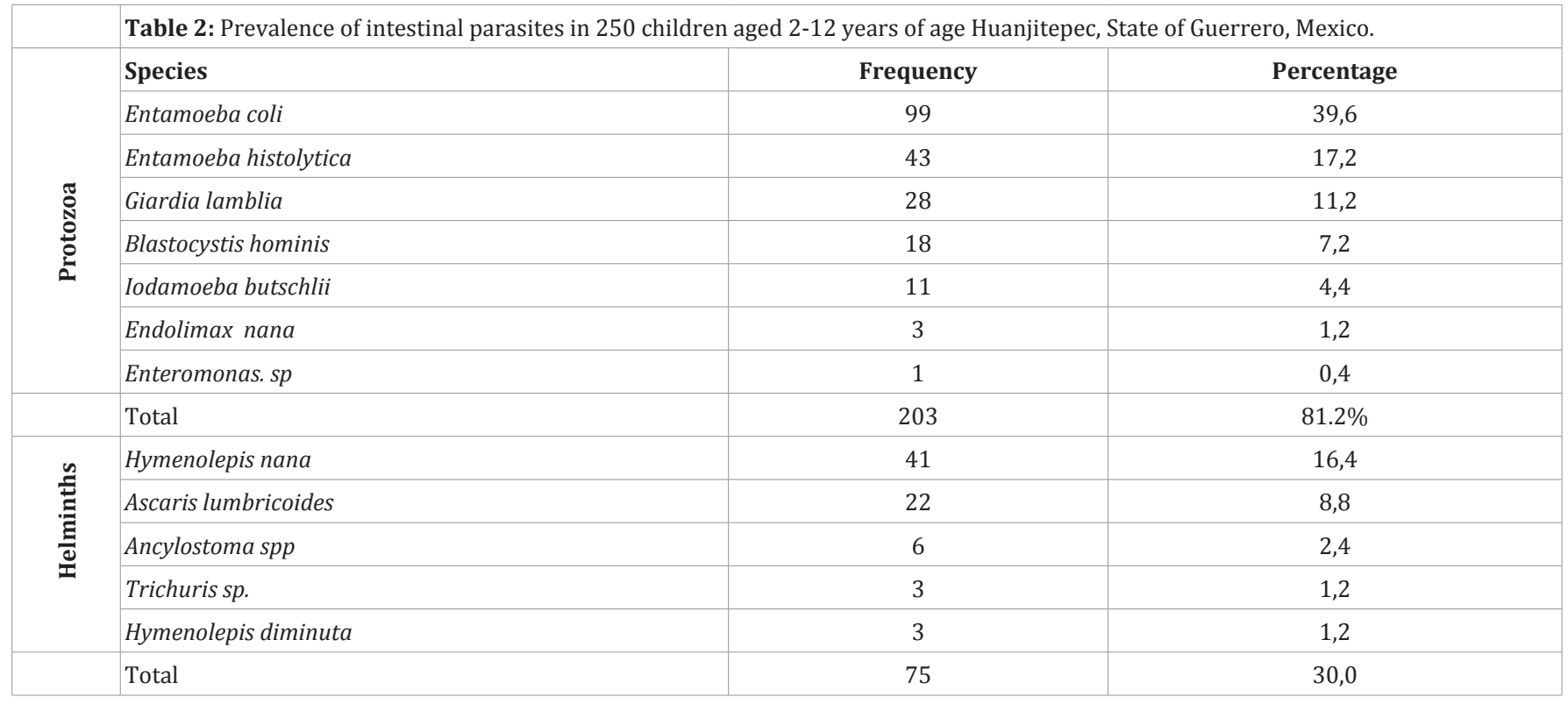

Table 3: Prevalence of E. coli * by age group of children Huajintepec, Guerrero, Mexico.

\begin{tabular}{|c|c|c|c|c|c|c|c|c|c|c|c|c|c|}
\hline & & \multicolumn{11}{|c|}{ Age (years) } & \multirow{2}{*}{ Total } \\
\hline & & 10 & 11 & 12 & 2 & 3 & 4 & 5 & 6 & 7 & 8 & 9 & \\
\hline \multirow{2}{*}{ E. coli } & Negative & 13 & 12 & 6 & 3 & 10 & 12 & 7 & 33 & 18 & 26 & 11 & 151 \\
\hline & Positive & 8 & 15 & 4 & 1 & 2 & 3 & 6 & 11 & 23 & 12 & 14 & 99 \\
\hline \multicolumn{2}{|c|}{ Total } & 21 & 27 & 10 & 4 & 12 & 15 & 13 & 44 & 41 & 38 & 25 & 250 \\
\hline
\end{tabular}

Table 4: Prevalence of E.coli * grade level in children Huajintepec, Guerrero. Mexico.

\begin{tabular}{|c|c|c|c|c|c|c|c|c|}
\hline & & \multicolumn{6}{|c|}{ School degree } & \multirow[b]{2}{*}{ Total } \\
\hline & & 1 & $2^{\circ}$ & $3^{\circ}$ & $4^{\circ}$ & $5^{\circ}$ & $6^{\circ}$ & \\
\hline \multirow{2}{*}{ E. coli } & Negative & 44 & 21 & 29 & 13 & 21 & 23 & 151 \\
\hline & Positive & 14 & 25 & 14 & 14 & 11 & 21 & 99 \\
\hline \multicolumn{2}{|l|}{ Total } & 58 & 46 & 43 & 27 & 32 & 44 & 250 \\
\hline
\end{tabular}

Table 5: Prevalence of E. histolytica* by age group in children from Huajintepec, Guerrero, México.

School Degree.

\begin{tabular}{|c|c|c|c|c|c|c|c|c|}
\hline & & \multicolumn{6}{|c|}{ Grade } & \multirow[t]{2}{*}{ Tota } \\
\hline & & 1 & 2 & 3 & 4 & 5 & 6 & \\
\hline \multirow{2}{*}{ E. histolytica } & Negative & 52 & 32 & 35 & 19 & 29 & 40 & 207 \\
\hline & Positive & 6 & 14 & 8 & 8 & 3 & 4 & 43 \\
\hline Total & & 58 & 46 & 43 & 27 & 32 & 44 & 250 \\
\hline
\end{tabular}

specific geographical and ecological characteristics of the site $[2,17,18]$. Comparison of results from studies performed in other Latin American countries, in similar socioeconomic and climatological conditions, with those of Huajintepec revealed different prevalences of parasitism. Studies performed by Ordoñez and Angulo [19] in children of 2 to 7 years of age in La Hormiga, a community of the Colombian Amazonia, revealed
$86.1 \%$ of intestinal parasitism, a higher value than that reported in our study, in contrast to a $30 \%$ of malnourished children, a value lower than ours. In studies performed in Valencia, state of Carabobo, Venezuela, Barón reported in 2007 the presence of parasitoses in $58.4 \%$ of children aged from 3 to 14 years [20], Lacoste et al. (2012)[17] reported an 89.7\% prevalence of parasitoses in children under 15 years of age of the community of 
Vegón de Nutrias, state of Barinas. Brandelli et al. [21], in Brazil, reported $90.5 \%$ of intestinal infections in children aged from 1 to 12 years in an indigenous population of Porto Alegre. Urban populations also suffer from this condition; studies performed by Núñez-Fernández et al. [18] in children from Habana, Cuba, revealed $68.5 \%$ of intestinal infections in children older than 2 years.

Regarding the nutritional status, results of this study reveal that $82.4 \%$ of the children were underweight and $68 \%$ coursed with intestinal parasitoses. This high percent of malnutrition could mean that the deterioration of the nutritional status originated from deficiencies in the quantity and quality of their food starting at the time of maternal milk weaning, a period in which gastrointestinal infections and malnutrition generally start, as until then the infant had been protected by breast feeding. Studies performed by Solano et al. [22] in the South of Valencia, the state of Carabobo in Venezuela, revealed 37.0\% of malnutrition and 49.6\% were parasitized. In Mexico, GutiérrezJiménez et al. in 2013[13], studied 250 indigenous children from three communities in the South of Mexico and found values of over $40 \%$ of different degrees of malnutrition. Amare et al. [23], reported, in Ethiopia, $25.5 \%$ of malnutrition, a value quite below the one found in the present study.

There are many different factors that contribute either directly or indirectly to the presence of nutritional concerns. Among them, consumption of an inadequate diet and the presence of intestinal infections, which interfere with the absorption and utilization of the ingested nutrients, stand out. Indirect causes are related to the economical conditions of the people, i.e., the levels of poverty, which is considered the main cause of malnutrition, aside from the insufficient availability of food both qualitatively and quantitatively. The limited access to food and the deficient quality of health services constitute the binomial malnutritioninfection [1].

The nutritional status of the preschool and school population is directly related to the growth and development of their future life stages. To attain an optimal development, it is essential for the child to receive adequate feeding, mainly during the first year of life, in which growth and brain development are fundamental; if not, functional and structural irreversible alterations, even death, can occur. To protect the child during this period, breastfeeding is essential $[6,7,24,25]$.

The high malnutrition index detected in the children of second and third-grade results, from the socioeconomic, cultural and ecological conditions prevailing in the studied community. Poverty is the factor responsible for the high degree of child malnutrition and constitutes the axis that conditions the lack of resources, the poor access to education, inadequate ingestion of foods (most feed on a hypocaloric and hypoproteic diet), and repeated disease events. These events in the short term influence the high morbidity and mortality indices, and in the long term are manifested in a lower intellectual capacity and a higher propensity to develop metabolic and cardiovascular diseases [15].
Chronic malnutrition is more frequent in children under 5 years of age, a period in which it contributes largely to the high morbidity and mortality indices. A child with chronic malnutrition presents delayed growth characterized by a low size for the age, indicating that the individual has been subjected to long periods of lacking the necessary nutrients, sacrificing the size to maintain the energy required to maintain the function of vital organs, and increasing the risk for diseases and alterations of the physical and intellectual development [24]. The delay in growth can have started before birth, while still in the womb; being more marked during pregnancy and during the first 2 years of life, consequences are irreversible and will be apparent for the rest of the individual's life [3]. Because of the influence that the nutritional status can have on the incidence of intestinal parasitoses, it is advisable to evaluate them as early as possible to facilitate the necessary actions to warrant an optimal development and growth.

Poverty and the deficient health conditions derived from it can contribute to helminths and protozoan infections that will impact the nutritional status of the individual. It is important to point out that intestinal parasites, through different mechanisms related to the type of enteropathogen, deprive the organism of nutrients [22]. To understand how and why intestinal parasites affect the nutritional status of children it is necessary to mention the possible mechanisms by which the intestinal parasites found in this study deprive the organism of the nutrients and, hence, foster malnutrition of the host. One of these mechanisms is the inflammatory response mediated by cytokines that produces loss of appetite, aside from having a deleterious effect on the metabolism of proteins [26]. Another involved mechanism is a diminution in the intestinal absorption of nutrients, due to an increase in intestinal peristalsis caused by injuries to the mucosa or the presence of a large amount of parasites in the duodenal epithelium. This is the case of Giardia lamblia infection, which exerts an adverse effect on growth and development affecting the nutritional status by impeding absorption of nutrients, vitamins A, D, E, K, B12, folic acid, and fatty acids. The atrophy of intestinal villi caused by the parasite diminishes the production of disaccharides affecting absorption of lactose, saccharide, and maltose. The characteristic post-prandial abdominal pain caused by $G$. lamblia drives children to stop eating [27]. Some reports suggest that the mechanism by which the infection affects the nutritional status is through the diminution in food ingestion and changes in eating preferences, as a consequence of sensory, neuronal and hormonal factors that modulate food ingestion [22].

Infection by E. histolytica is more frequent in individuals with carbohydrate-rich and protein-depleted diets. This parasite affects the nutritional status of the child by sacking the nutrients from the ingested food and avoiding their absorption mainly by increasing intestinal peristalsis through mucosal damage and producing diarrhea with mucus and blood (amoebic dysentery). The effects on the nutritional status depend on the existing nutritional status, the susceptibility of the host, and the virulence of the strain [28].

For the nutrition-parasitosis association, a higher prevalence 
of intestinal parasites has been found in malnourished children. The nutritional deficiency is not easy to explain, mainly when there are multiple coexisting deficiencies in the population within an economically weak environment with precarious sanitary conditions. The deficient sanitary conditions of the studied population derived from poverty foster infections by helminths and protozoan that impact the nutritional status of the individual [28-30].It must be noted that in this work, we were able to identify a specific and significant association between E. coli and the high percentage of malnourished children. However, we cannot affirm categorically that microorganism, considered as a commensal protozoan, is a direct cause of malnutrition, because malnutrition is multifactorial and the parasitosis was a contributing factor but not determinant. However, its high frequency is an indicator of the profound environmental, water, and food contamination with human feces [31].

The overcrowding living conditions affecting $22.9 \%$ of the population of Huajintepec facilitate the transmission of hymenolepiasis, helminthiasis, caused by Hymenolepis nana and Hymenolepis diminuta, which are considered as the most frequent cestodiasis in preschool and school children.

H. nana was detected in this study $(16.4 \%)$. The mechanism of damage to the host is mainly due to the sacking of nutrients from the diet through the tegument of the parasite and by the high number of worms in the host. A person infected with $H$. nana can increase the number of hosted parasites due to a mechanism of internal or endogenous self-infection, in which the eggs of the parasite can complete their biological cycle inside their own intestine and produce massive infections with great impacts on the growth and development of the host [32].

Parasitic infections mainly those caused by intestinal nematodes are very prevalent, and their adverse effect on the nutritional status has been demonstrated, particularly in those highly parasitized. Infection with Ascaris lumbricoides, when mild, remains asymptomatic for long periods of time; however, when the infection is severe it can produce severe digestive symptoms, vital risk complications, and nutritional alterations [33]. The parasite interferes with digestion and with the use of ingested proteins, with an increase in the fecal loss of nitrogen, less absorption of fats, and loss of fats in feces, as well as a deficit of vitamin $A$ and lower lactose tolerance. It is estimated that 25 adult ascarids can induce a loss of $4 \mathrm{~g}$ of proteins from a diet containing 30 to $40 \mathrm{~g}$ of protein, thereby contributing to malnutrition that is manifested by delay in growth and development of infants. In some cases, the presence of just one ascarid can cause a medical emergency that, if not treated, can lead to death [31]. It is worthwhile mentioning that in these conditions, eggs of ascarids can survive up to 15 years [34].

Conditions of living quarters are clearly recognized for a long time as one of the main social determinants of human health. Among others, the lack of hygiene, precarious sanitary conditions, and overcrowding are some of the risks regarding housing. In the study area, the physical conditions of the environment are favorable for the maturation and permanence of the infective stages of different parasites. Likewise, the habit of roaming around barefooted, of playing on the ground and the deficiency in handling human wastes all constitute an optimal scenario for the transmission of the found geohelminths.

The frequency of Ascaris lumbrioides and Ancylostomatidae found in the studied population of children was favored by the conditions of the floor prevailing in the living quarters; $50.8 \%$ of the houses had floors of soils, which is a favorable environment for the development and maintenance of infecting stages of both helminths. Contamination of the soil in the living quarters with wastes from dogs facilitates the transmission of zoonoses, such as: toxocariasis, trichuriasis, and cutaneous larva migrans, also known as creeping eruption $[2,35,36]$. Both humans and dogs become infected by the ingestion of infectious feces of the parasites (that is, larval eggs and free larvae) present in the soil. Toxocariasis is caused by Toxocara canis, ascarid of dogs. In the soil, the eggs evolve to larval eggs in three to four weeks. When these larval eggs are ingested by children of 1 to 4 years with antecedents of geophagia, the larvae released in their intestine migrate through different internal organs where they produce two clinical entities: visceral toxocariasis or visceral larva migrans and ocular toxocariasis or ocular larva migrans, capable of producing visual alterations that can lead to loss of vision in the affected eye [37].

Trichuriasis is caused by Trichuris trichiura (human trichocephalus), but can be caused occasionally by Trichuris vulpis (canine trichocephalus) as a consequence of the contamination of the soil with feces of parasitized dogs. The eggs of the worm can become embryos in the soil and be infectious [38-40].

For Ancylostomatidae, for instance, the larvae of Ancylostoma duodenale, present in the soil contaminated with human feces, penetrate the human skin and reach the intestine. Both Trichuris trichiura and Ancylostoma duodenale are hematophagous, and can cause anemia, mainly in children under 10 years of age, with the corresponding impact on their nutritional status. Uncinariasis is an important factor that favors the development of anemia due to iron deficiency. It has been calculated that infections by 350 Ancylostomatidae cause a daily loss of $10 \mathrm{~mL}$ of blood or 2 $\mathrm{mg}$ of iron [41]. Iron deficiency is the main cause of anemia in developing countries and the most vulnerable groups are nursing children, preschool and school children, women in reproductive age and pregnant women. In children, the main cause of this deficiency is due to the increase in nutritional iron requirements related to growth during the developmental stage. Additionally, the nutritional iron status of individuals and populations depends on the amount and quality of iron coming from the diet, of its bioavailability in food, and the loss of iron by the organism [20].

Unfortunately, it was not possible to take blood samples in the studied community, because of the sacred role played by blood in these communities based on their religious beliefs. Hence, it was not possible to assess whether the studied community had anemia that could be associated with the malnutrition and the presence of parasites. Anemia is an indirect indicator of iron and other micronutrient (vitamins A, B12, and folic acid) deficiencies, 
whereas the decrease in the size of children older than 5 years is an indicator of an inadequate diet, usually deficient in nutrients during the first two years of life, particularly in rural communities and in extreme poverty [42]. Larvae from the A. caninum, when entering the skin of children under the age of 5 years produces a dermatitis known as cutaneous larva migrans or creeping eruption [43].

Although currently there are diverse social campaigns like: the fight against poverty sponsored by the Social Development Ministry (SEDESOL for its acronym in Spanish), "1 kg of help", rounding up of cents when buying at the supermarkets, or the "soccer goal for nutrition"; these are not enough to improve the health status of the population. The anti-parasites campaigns performed twice a year in March-April and August-September, have only been relatively successful in rural areas. However, they are still not enough for the control of protozoan produced by open defecation, since intestinal parasitoses constitute the second most frequent transmissible disease in Mexico. To eradicate definitively enteroparasitoses, antiparasitic treatment must be administered every three months in regions of high endemicity, with more than $50 \%$ of infections, this must be associated to hygiene measures and environmental sanitation, such as an adequate disposal of human and animal feces to interrupt the biological cycle of each parasite and thereby diminish dissemination. Likewise, it cannot be postponed any further to improve the food of children less than 5 years of age with diets including the minimal daily requirements of protein to enhance the efficacy of the immune response against parasitoses and to improve the physical and mental development. All these actions will undoubtedly induce a cleaner environment and a better growth and development of the children of this type of communities.

\section{Conclusion}

Malnutrition and parasitoses are still important health issues in the mountains of the state of Guerrero, as revealed by the poor nutritional status of the children, which is higher than recently reported for our country by other authors. These findings suggest that factors like the low socioeconomic level, demographic data, and open air defecation are the main causes of intestinal infections and contribute importantly to the poor nutritional status of the population. These data point out the need for an integrated approach, addressed at a reduction of poverty, environmental sanitation based on minimal requirements of electricity, sewage, latrines, and septic tanks, availability of potable water, improvement in the quality of food, preferably with animalorigin proteins, which, besides improving weight development, will contribute to the bioavailability of the hem group to prevent anemia and improve the immune system's performance. In addition to measures like hygiene education, family planning programs, anti-parasitic therapy every three months, to control the transmission of parasites. All these actions will undoubtedly improve the nutritional status and development of children not only in rural areas but of the population in general.

\section{Acknowledgement}

We declare that this work has not been published or subjected to any arbitration in whole or in part by any of the authors. We also agree that the responsibility for the publication and first author is MD. Ignacio Martínez-Barbabosa and the order of authorship is: Hilda Ortiz Perez, José Marcos Aguilar Venegas, Rebeca Cordova Moreno, Enrique Gaona, Ana MariaFernandez Presas. The correspondence will be directed to Dr. Fernandez Presas.

\section{References}

1. Taheri F, Namakin K, Zarban A, Sharifzadeh G. Intestinal Parasitic Infection among School Children in South Khorasan Province, Iran. J Res Health Sci. 2011;11(1):45-50.

2. Lemus-Espinoza D, Maniscalchi MT, Kiriakos D, Pacheco F, Aponte C, Villarroel O, et al. Enteroparasites in children under 12 years old at Anzoategui State, Venezuela. Rev. Soc Ven. Microbiol. 2012;32(2): 139-147.

3. United Nations Fund for Children. State of the World's Children. New York: UNICEF; 2012. Available from: http://www.unicef.org/

4. WHO. Physical status: the use and interpretation of anthropometry. Report of a WHO Expert Committee. WHO Technical Report Series No. 854. Geneva: World Health Organization. 1995.

5. Quihui-Cota L, Morales-Figueroa GG. INTESTINAL PARASITISM IN SCHOOLCHILDREN TREATED WITH ALBENDAZOL in northeastern Mexico: A PILOT STUDY. Biotecnia. 2012;XIV(2):32-39.

6. Black RE, Morris SS, Bryce J. Where and why are 10 million children dying every year? Lancet. 2003 Jun;361(9376):2226-34.

7. Moore SR, Lima AA, Guerrant RL. Infection: Preventing 5 million child deaths from diarrhea in the next 5 years. Nat Rev Gastroenterol Hepatol. 2011;8(7):363-4. doi: 10.1038/nrgastro.2011.103.

8. Abba K, Sinfield R, Hart CA, Garner P. Pathogens associated with persistent diarrhea in children in low and middle income countries: BMC Infect Dis. 2009;9:88. doi: 10.1186/1471-2334-9-88.

9. WHO(eds)Physical Status: The Use and Interpretation of Anthropometry. Report of a WHO Expert Committee. WHO Technical Report Series 854 Geneva World Health Organization. American Journal of Human Biology. 1996; 8(6):786-787. DOI: 10.1002/ (SICI)1520-6300(1996)8:6<786.

10.Losano L, Acuña Moron SA, Sánchez A. INTESTINAL PARASITIC INFESTATION AND OTHERS INFECTIOUS BACKGROUNDS INFLUENCE IN THE ANTROPOMETRIC NUTRITIONAL STATUS OF CHILDREN IN POVERTY. Parasitol Latinoam. 2008;63:12-19.

11. National Health and Nutrition inquest. National Results. 2012.

12. Sánchez de la Barquera-Ramos MA, Miramontes-Zapata M. Intestinal parasitoses in 14 rural communities in the highlands of Mexico. Rev Latinoamer Patol Clin. 2011;58 (1):16-25.

13. Gutierrez-Jimenez J, Torres-Sanchez MG, Fajardo-Martinez LP, Schlie-Guzman MA, Luna-Cazares LM, Gonzalez-Esquinca AR, et al. Malnutrition and the presence of intestinal parasites in children from the poorest municipalities of Mexico. J Infect Dev Ctries. 2013;7(10):741-7. doi: 10.3855/jidc.2990.

14. Morales Espinoza EM, Sánchez-Pérez HJ, García- Gil MM, Vargas morales G, Méndez-Sánchez JD, Pérez-Ramírez M. Intestinal parasites in children, in highly deprived areas in the border region of Chiapas, Mexico. Salud Publica Mex. 2003;45(5):379-88.

15. National Institute of Statistics and Geography, Population and Housing 


\section{Census. 2010.}

16. World Medical Association. World Medical Association Declaration of Helsinki: ethical principles for medical research involving human subjects. JAMA. 2013;310(20):2191-4. doi: 10.1001/ jama.2013.281053.

17. Lacoste LE, Rosado GFM, Núñez FA, Rodríguez P MS, Medina FIC, Suárez MR. Aspects on children epidemiology of intestinal parasites in Vegón Nutrias, Venezuela. Rev Cubana Hig Epidemiol. 2012;50(3):330-339.

18. Núñez FFÁ, Hernández PSM, Ayllón VLL, Alonso MMT. Epidemiological findings in intestinal parasitic infections from a group of hospitalized children with diarrhea. Rev Cubana Med Trop. 2013;65 (1): 26-35.

19. Ordoñez LE, Angulo ES. [Malnutrition and its association with intestinal parasitism among children from a village in the Colombian Amazonian region]. Biomedica. 2002;22(4):486-98.

20. Barón MA, Solano RL, Páez MC, Pabón M. Iron nutritional status and intestinal parasitosis in children from Valencia, Carabobo, Venezuela Venezuelan Annals of Nutrition. 2007;20(1):5-11

21. Brandelli CL, de Carli GA, Macedo AJ, Tasca T. Intestinal parasitism and socio-enviromental factors among Mbyá-GuaraniIndians, Porto Alegre, Río Grande do Sul, Brazil. Rev Inst Med Trop Sao Paulo. 2012;54(3):119-22.

22. Solano L, Acuña I, Barón MA, Morón SA, Sánchez AS. Intestinal parasitic infestation and others infectious background influence in the antropometric nutritional status of children in poverty. Parasitol Latinoam. 2008; 63(1-2-3-4):12 19.

23. Amare B, Ali J, Moges B, Yismaw G, Belyhun Y, Gebretsadik S, et al. Nutritional status, intestinal parasite infection and allergy among school children in Northwest Ethiopia. BMC Pediatrics. 2013;13(7)1471-2431. doi:10.1186/1471-2431-13-7

24.Wachs TD. Relation of mild-to-moderate malnutrition to human development: correlation studies. J Nutr. 1995;125(8 Suppl):2245S$2254 \mathrm{~S}$.

25. Baqui AH, Ahmed T. Diarrhoea and malnutrition in children. BMJ. 2006;332(7538):378.

26.Zaph C, Cooper PJ, Harris NL. Mucosal immune responses following intestinal nematode infection. Parasite Immunol. 2014 ;36(9):439-52. doi: 10.1111/pim.12090

27. Giraldo-Gómez JM, Lora F, Henao LH, Mejía S, Gómez-Marín JE. Prevalence of giardiasis and intestinal parasites in pre-school children from homes being attended as part of a state program in Armenia, Colombia. Rev Salud Publica (Bogota). 2005;7(3):327-38.

28. Santos VR, Nunes J da S; Camargo JA, Rocha EM, Fontes G, Camargo LM. High occurrence of Entamoeba histolytica in the municipalities of Ariquemes and Monte Negro, State of Rondônia, Western Amazonia, Brazil. Rev Inst Med Trop Sao Paulo. 2013;55(3). doi: 10.1590/S003646652013000300010
29. Jex AR1, Liu S, Li B, Young ND, Hall RS, Li Y, et al. Ascaris suum draft genome. Nature. 2011;479(7374):529-33. doi: 10.1038/nature10553.

30. Campos Ponce M, Incani RN, Pinelli E, Ten Kulve N, Ramak R, Polman $\mathrm{K}$, et al. Are intestinal parasites fueling the rise in dual households in Venezuela? Trans R Soc Trop Med Hyg. 2013;107(2):119-23. doi: $10.1093 /$ trstmh/trs014.

31.Zonta ML, Navone GT, Oyhenart EE. INTESTINAL PARASITES in PRESCHOOL and SCHOOL AGE CHILDREN: CURRENT SITUATION in URBAN, PERIURBAN and RURAL POPULATIONS in BRANDSEN, BUENOS AIRES, ARGENTINA. Parasitol. latinoam. 2007,62(1-2),54-60.

32. Atías A. Parasitología Clínica. Santiago, Chile. Publicaciones Técnicas Mediterráneo, 2006; p.163-170.

33. Defagot LM, Pizzi HL, Tomás AF, Pizzi RD, Dib MD. Ascariasis: death by suffocation. Revista de Salud Pública. 2013;17(4):31-39.

34. O'Lorcain P, Holland CV. The public health importance of Ascaris lumbricoides. Parasitology. 2000;121 Suppl:S51-71.

35. Traversa D, Frangipane di Regalbono A, Di Cesare A, La Torre F, Drake J, Pietrobelli M. Enviromental contamination by canine geohelminths. Parasit Vectors. 2014;7:67. doi: 10.1186/1756-3305-7-67.

36. Nundu Sabiti S, Aloni MN, Linsuke SW, Ekila MB, Situakibanza HT, Polman K, et al. Prevalence of geohelminth infections in children living in Kinhasal. Arch Pediatr. 2014;21(6):579-83. doi: 10.1016/j. arcped.2014.03.003.

37. Schantz PM. Toxocara larva migrans now. Am J Trop Med Hyg. 1989;41(3 Suppl):21-34

38. Vásquez T O, Martínez B I, Romero C R, Valencia R S, Tay Z J. [MIXED INFECTION BY TRICHURIS TRICHIURA AND TRICHURIS VULPIS]. Rev Gastroenterol Peru. 1997;17(3):255-258.

39. Tee MH, Lee YY, Majid NA, Noori NM, Raj SM. Growth reduction among primary schoolchildren with light trichuriasis in Malaysia treated with albendazole. Southeast Asian J Trop Med Public Health. 2013;44(1):19-24.

40. Márquez-Navarro A1, García-Bracamontes G, Alvarez-Fernández BE, Ávila-Caballero LP, Santos-Aranda I, Díaz-Chiguer DL. Trichuris vulpis (Froelich, 1789) infection in a child: a case report. Korean J Parasitol. 2012;50(1):69-71. doi: 10.3347/kjp.2012.50.1.69.

41. Roche M, Layrisse M. The nature and causes of "hookworm anemia". Am J Trop Med Hyg. 1966;15(6):1029-102.

42. Ramakrishnan U, Neufeld LM, Flores R, Rivera J, Martorell R. Multiple micronutrient supplementation during early childhood increase child size at 2 y of only among high compliers. Am J Clin Nutr. 2009;89(4):1125-31. doi: 10.3945/ajcn.2008.26874.

43. Gamboa MI, Navone GT, Orden AB, Torres MF, Castro LE, Oyhenart EE. Socio-environmental conditions intestinal parasite infections and nutritional status in children from a suburban neighborhood of La Plata, Argentina. Acta Trop. 2011;118(3):184-9. doi: 10.1016/j. actatropica.2009.06.015 